\title{
Analytical Modeling and Optimization of Logarithmic Sprag Clutch Considering Profile Modification
}

\author{
Chuang Huang $(\mathbb{D}$, Yongqiang Zhao $\mathbb{D}$, and Ming Liu \\ School of Mechatronics Engineering, Harbin Institute of Technology, Harbin, China \\ Correspondence should be addressed to Yongqiang Zhao; hcxjtu@163.com
}

Received 7 May 2018; Accepted 12 September 2018; Published 7 November 2018

Academic Editor: Hamid Toopchi-Nezhad

Copyright ( $\odot 2018$ Chuang Huang et al. This is an open access article distributed under the Creative Commons Attribution License, which permits unrestricted use, distribution, and reproduction in any medium, provided the original work is properly cited.

\begin{abstract}
A new analytical model of a logarithmic sprag clutch considering profile modification is proposed to reflect the effect of profile parameters on the dynamic contact pressure distribution during the engagement, especially the edge stress of a sprag roller. In the model, a nonlinear iteration method of normal force including the logarithmic profile model with three parameters and structural deformations of races is given. The alternate friction model considering stationary and rate-dependency friction is formulated and applied in the contacts between the sprag rollers and races. Then, the kriging model describing the relationship between the maximum contact stress throughout the engagement and the profile parameters is established and validated, and the krigingbased optimization of the design parameters is proposed using genetic algorithms. In subsequent analysis, based on the presented analytical model and optimization process, the maximum contact stress throughout the engagement can decrease greatly through optimizing the profile parameters. Therefore, the results of the present paper could aid in the design of the logarithmic sprag clutch and help avoid end crush failure and low cycle fatigue of the sprag roller.
\end{abstract}

\section{Introduction}

The sprag clutch is the type of freewheel clutches most commonly used today due to its lower manufacturing costs and high reliability, and it can transmit torque moment in one direction through friction contact and allow idling in the opposite direction. In order to facilitate the standardization of applications, the sprags in the clutch have attained a high degree of refinement with a precision-machined engagement curve such as a circular profile and logarithmic spiral profile, which is a prerequisite for precise engaging and long operating life. Therefore, the performance of the sprag clutch depends on the geometry of the sprag roller, especially the parameters of the engagement curve. Lynwander et al. [1] presented the design procedure for a multiarc sprag clutch from the view of static, including the deformations of the components and the geometric relationship. Kish [2] further proposed the iterative design method for a single-arc sprag clutch containing additional centrifugal deformation of the outer race. However, the dynamic stress throughout the engagement is much higher than the static stress, and the concentrated stress appears at both ends of the sprag roller because of the edge effect in line contact. Due to frequent start-up and variable speed operation, the dynamic stress with the edge effect in engaging may lead to end corrupt of the sprag roller or low cycle fatigue. To offer a theoretical basis for the dynamic design of the logarithmic spiral sprag clutch in this paper, it is necessary to construct a logarithmic spiral sprag clutch model that can consider the geometry, the dynamic interactions of the components, and the profile modification which eliminates the concentrated stress.

Figure 1 shows a cut view of a complete logarithmic sprag clutch and components of the clutch. Such a logarithmic sprag clutch is composed of five components: a cylindrical inner race, a cylindrical outer race, accurately formed sprag rollers with a logarithmic profile, a sprag cage, and energizing springs. The two races form a cylindrical annular space, in which each sprag roller is essentially a strut placed between the races by the sprag cage. The sprag rollers transmit power from one race to the other by an engaging action when either race is rotated in the driving direction, while rotation in the other direction disengages the sprag rollers and the clutch is free, or overruns. Either race may be the driven member or the driving member. At the initial engagement position, the 


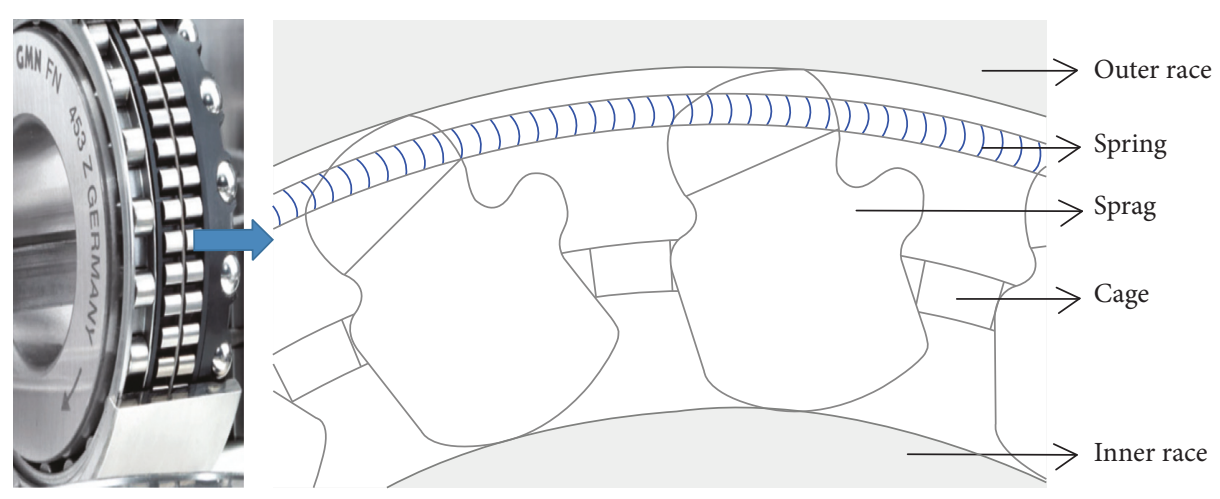

FIGURE 1: A cross-sectional view of the GMN logarithmic sprag clutch model.

energizing springs hold the sprag rollers in contact with the races. Regarding the characteristic of the logarithmic curve, the logarithmic sprag clutch has an advantage that the engagement angles of the sprag rollers are stabilized in all zones of contact over the entire engagement zone.

Because the sprag clutch is a type of friction component, which is characterized by geometry, contact nonlinearity, and friction, its dynamic performance in engaging is thus deeply affected by these factors, and the analytical model of the sprag clutch has been studied extensively over the last twenty years.

Chassapis and Lowen [3] presented a total stiffnessdamping model of the circular sprag clutch adapted in a press-feed mechanism, using a linear damping model to express the energy dissipation. Based on the work, Xu and Lowen [4] improved the total stiffness-damping model using a nonlinear damping model. Further, Xu and Lowen [5] proposed a complete mathematical model firstly considering the dynamic contact nonlinearity and pointed out that the edge effect should be taken into consideration to improve the accuracy of the model. However, the friction between the sprag rollers and the races are assumed to pure rolling and the structural deformations of the races are neglected in Xu's proposed model. Vernay et al. $[6,7]$ used a Coulomb friction model to model the dynamic friction in contacts between the sprag rollers and the inner race, and the structural deformations of the races are firstly considered. To further improve the accuracy of the model, Huang et al. [8] developed a multiarc clutch model considering the geometry and interactions, in which a novel nonlinear iteration method of the normal contact force focusing on the varied contact radius and edge effect is proposed, and the alternate friction model considering stationary and rate-dependency friction is formulated. As for modeling the logarithmic spiral clutch, only Liu et al. [9] presented a mathematical model of the logarithmic sprag clutch based on Xu's research, but also assumed the stationary friction in contacts and neglected structural deformations of the races, not to mention the roller profile modification.

Most studies on the profile design for cylindrical contact are about roller bearings. Lundberg [10] introduced a logarithmic function to the profile design of the roller, which can ensure uniform contact pressure distribution between the roller and races, but it has the drawback of discontinuity at the end of the roller. Johns and Gohar [11] revised Lundberg's logarithmic function to obtain continuous uniform contact pressure distribution, especially under the condition of misalignment between the roller and races. In order to facilitate engineering application, Fujiwara and Kawase $[12,13]$ gave a logarithmic crowing formula by introducing three design parameters into Johns and Gohar's formula, offering a new design approach that prevented edge loading due to misalignment. Kamamoto et al. [14] optimized the crowing profile of the cylindrical roller bearing, and results showed that the contact pressure became axially uniform and fatigue life was improved. Kumar et al. [15] optimized the fatigue life of the roller bearing by a genetic algorithm to obtain the chosen geometric parameter and two logarithmic profile parameters of the roller. However, regarding the profile design of the logarithmic sprag clutch, no research has been reported until now.

This paper will be organised as follows. In the following section, the calculation method of the normal force containing the roller profile model with three parameters and the friction force is presented, and then an analytical model of the logarithmic sprag clutch considering profile modification is established and validated. Subsequently, in the next section, a kriging model describing the relationship between the maximum stress and the three design parameters is developed and validated, and the kriging-based optimization procedure for design parameters is proposed using the genetic algorithm. In the results and discussion section, the effect of design parameters on contact pressure distribution is investigated, and the optimization of design parameters under different torques applied is discussed. In the last section, some conclusions are given.

\section{The Analytical Model of Crowned Logarithmic Sprag Clutch}

2.1. Geometry Parameter Description. Figure 2 shows a simplified configuration of a complete logarithmic sprag clutch at the initial engagement position, and the corresponding geometric parameters are labeled. $O$ is the common center of inner and outer circles for the races, $C_{g}$ is the centroid position of the sprag roller depending on its mass distribution, and points $A$ and $B$ are the contact points between the sprag roller and the inner race and outer race. It is assumed that the center of the outer circle $C_{e}$ is also the pole of the inner logarithmic curve, and thus the line $A C_{e}$ is the polar 


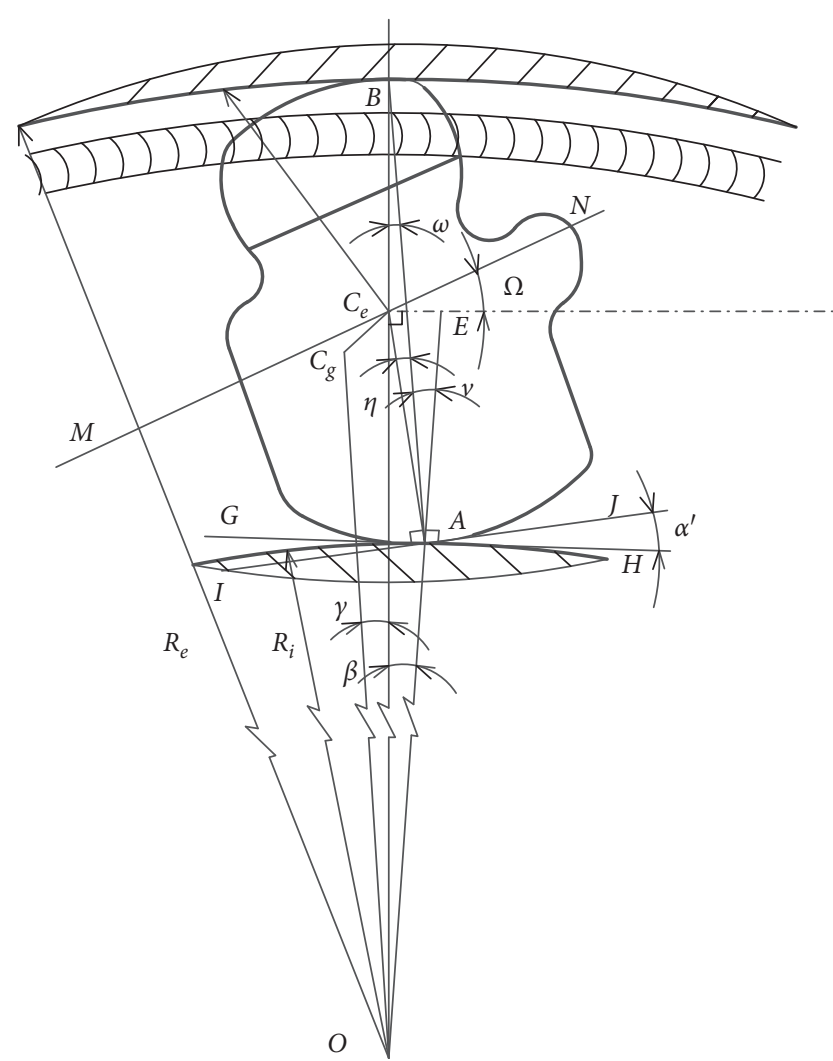

Figure 2: A three-design parameter logarithmic roller profile.

radius. The associated contact angles $v$ and $\omega$ are described by the line $A B$ with respect to the lines $O A$ and $O B$, and the angles $\beta$ and $\gamma$ are expressed by the line $O B$ with respect to the lines $O A$ and $O C_{g}$, respectively. The angle $\eta$ is presented by the lines $A B$ and $A C_{e}$, and the angle $\Omega$ between the horizontal line $C_{e} E$ and the line $M N$ is defined as the rotation angle. $R_{e}$ is the radius of the inner surface of the outer race, and $R_{i}$ is the radius of the outer surface of the inner race.

In addition to the above geometric parameters, a threedesign parameter logarithmic roller profile model is used to avoid edge stress concentration, shaping the axile sectional of the sprag roller. The logarithmic roller profile is shown in Figure 3, and its formulation is given as

$$
z(y)=-\frac{2 K_{1} Q}{\pi l E^{\prime}} \ln \left\{1-\left[1-\exp \left(-\frac{z_{m}}{A}\right)\right]\left(\frac{y-l / 2}{K_{2} l / 2}+1\right)^{2}\right\}
$$

where $z(y)$ is the crown drop at the axial position $y, E^{\prime}$ is equivalent Young's modulus, $Q$ is the load, $l$ is the effective length of the sprag roller, and $K_{1}, K_{2}$, and $z_{m}$ correspond to the crowning curvature, the ratio of the crowing region length to the effective roller length, and the crown drop at the crowing region ends, respectively.

\subsection{The Geometry Deformation Coordination}

2.2.1. The Deformations in Components. As shown in Figure 4 , with the rotation of the sprag roller during the

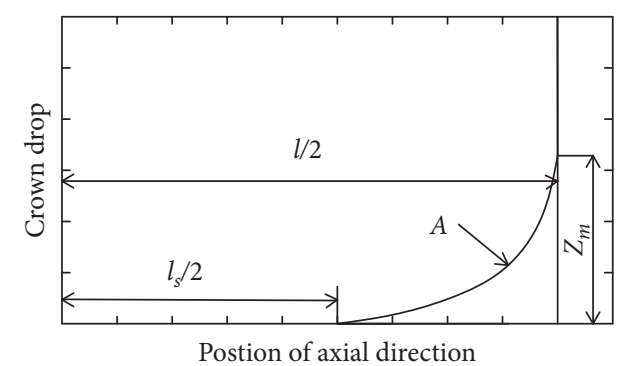

Figure 3: A schematic diagram of a logarithmic sprag clutch.

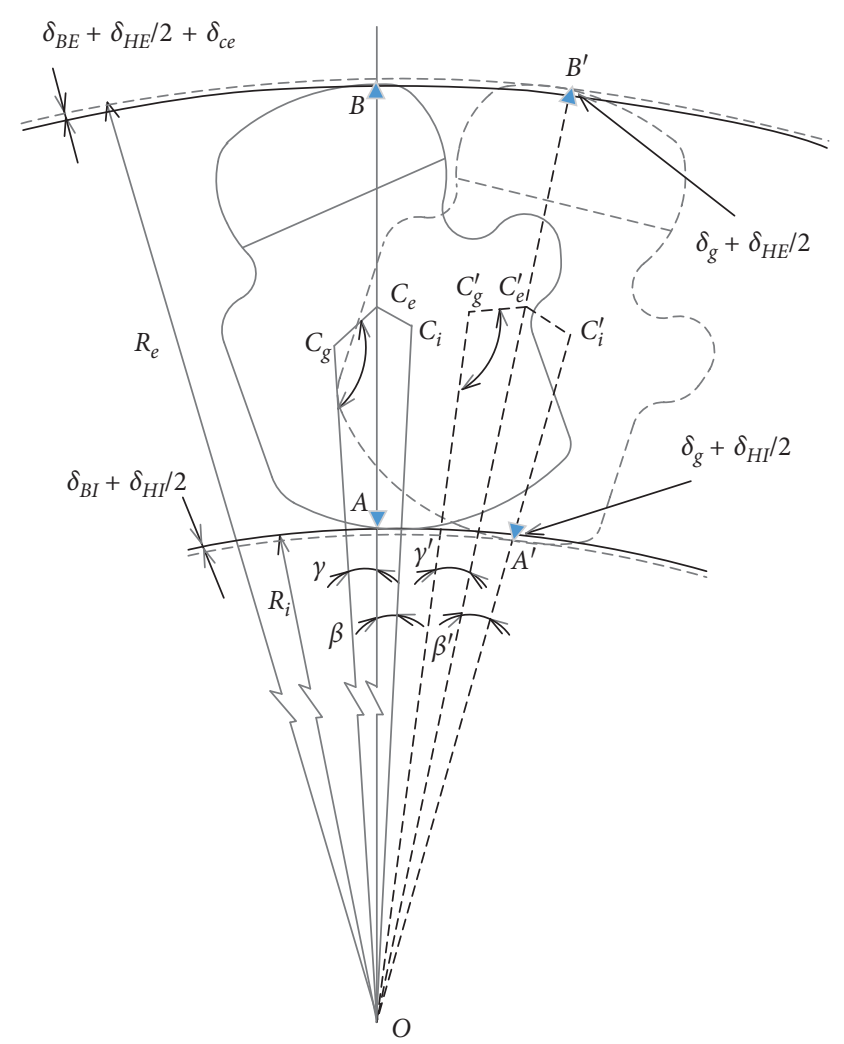

FIgURE 4: The deformations of components after rotation of the sprag roller.

engagement, two types of deformations are generated at the contacts: the local contact deformation between the sprag roller and races and the structural deformation of the races, which should be both considered in the analytical model. The local contact deformations of the sprag rollers interacting the inner race and outer races are defined as $\delta_{H I}$ and $\delta_{H E}$, respectively. The structural deformations of the inner and outer races are expressed as $\delta_{B I}$ and $\delta_{B E}$, and the structural deformation of the sprag roller is written as $\delta_{g}$. To consider the effect of high speed, the centrifugal deformation of the outer race is also included and defined as $\delta_{c e}$. The following discusses a calculation method for obtaining the above-described deformations and the formulation of basic geometric quantities after rotation.

The local contact deformations $\delta_{H E}$ and $\delta_{H I}$ are calculated by the slice method [16], in which the logarithmic roller profile model is included. As shown in Figure 5, the sprag 


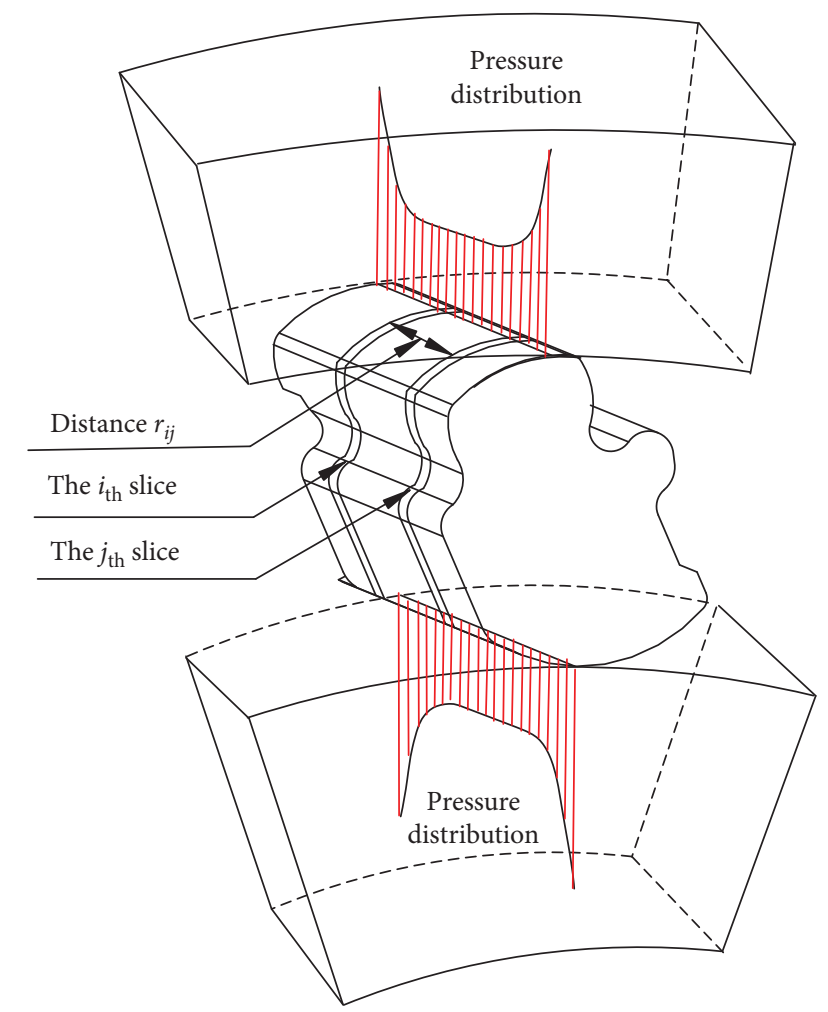

FIGURE 5: The slice method applied at contacts between the sprag roller and the races.

roller is axially divided into a certain number of slices with equal length, and the slices influence each other's deflection through the influence coefficient. Based on these, the expression between the load and the deflection of each slice can be obtained as follows:

$$
\begin{aligned}
{\left[\mathbf{S}_{w}\right]_{i} \cdot\{\mathbf{q}\}_{i} } & =\{\Delta\}_{i}, \\
{\left[\mathbf{S}_{w}\right]_{e} \cdot\{\mathbf{q}\}_{e} } & =\{\Delta\}_{e} .
\end{aligned}
$$

In each of the above equations, $\left[\mathbf{S}_{w}\right]$ is the matrix of weighted influence coefficients with a specific expression:

$$
\left[\mathbf{S}_{w}\right]=\frac{n}{\sum_{j, k} w_{j, k}}\left[\begin{array}{ccc}
s \cdot w_{j, k} & \cdots & s \cdot w_{j, n} \\
\vdots & \ddots & \vdots \\
& & \\
s \cdot w_{n, k} & \cdots & s \cdot w_{n, n}
\end{array}\right],
$$

$$
\text { for } j=1, \ldots, n, k=1, \ldots, n \text {, }
$$

where $s$ is the elastic compliance of each slice in contact with the inner or outer race, $\omega_{j, k}$ is the weighting function, which means that the unit pressure on the slice acts on the effect of deformation on slice $k$. Moreover, since the weighting function has the relationship $\omega_{j, k}=\omega_{k, j}$, $\left[\mathbf{S}_{w}\right]$ is a symmetric matrix.

$\{\mathbf{q}\}$ is the vector of unknown forces on each slice element of the sprag roller:

$$
\{\mathbf{q}\}=\left\{\begin{array}{c}
q_{j} \\
\vdots \\
q_{n}
\end{array}\right\}, \quad \text { for } j=1, \ldots, n .
$$

$\{\Delta\}$ is the vector of deflections belong to each slice element of the sprag roller:

$$
\begin{aligned}
& \{\Delta\}=\left\{\begin{array}{c}
\left(\delta_{j}-z(j)\right)^{1 / e x} \\
\vdots \\
\left(\delta_{n}-z(n)\right)^{1 / e x}
\end{array}\right\}, \quad \text { for } j=1, \ldots, n, \\
& z(j)=-\frac{2 K_{1} Q_{2}}{\pi l E^{\prime}} \ln \left\{1-\left[1-\exp \left(-\frac{z_{m}}{A}\right)\right]\right. \\
& \left.\cdot\left(\frac{(j-0.5) l / n-l / 2}{K_{2} l / 2}+1\right)^{2}\right\}
\end{aligned}
$$

where $z(j)$ is the crown drop on the slice $j, \delta_{j}$ is the deflection of the slice $j$ calculated by Hertz theory of line contact under load $q_{j}$, and thus $\delta_{j}-z(j)$ is the deflection of the slice $j$ considering profile modification.

The structural deformations of the races $\delta_{B I}$ and $\delta_{B E}$ are calculated by the Lame formula of thick-walled cylinder theory, and the expressions can be obtained as follows:

$$
\begin{aligned}
& \delta_{B I}=\frac{N_{b i} n}{2 \pi l E}\left[\frac{R_{i}^{2}+R_{i d}^{2}}{R_{i}^{2}-R_{i d}^{2}}-v\right], \\
& \delta_{B E}=\frac{N_{b e} n}{2 \pi l E}\left[\frac{R_{e d}^{2}+R_{e}^{2}}{R_{e d}^{2}-R_{e}^{2}}+v\right],
\end{aligned}
$$

where $E$ refers to the elastic modulus, $v$ represents Poisson's ratio, $l$ is the length of the sprag roller, $n$ is the number of the sprag rollers, $R_{e d}$ is the radius of the outer surface of the outer race, $R_{i d}$ is the radius of the inner surface of the inner race, and $N_{b i}$ and $N_{b e}$ represent the normal contact forces of the inner race and outer race, respectively.

The structural deflection of the sprag roller $\delta_{g}$ can be written as

$$
\delta_{g}=\frac{N_{b i}\left(R_{e}-R_{i}\right)}{b l E} .
$$

Moreover, based on the hollow disk theory, the expression of the additional centrifugal deformation of the outer race can be written as

$$
\delta_{c e}=\frac{R_{e}}{E} \frac{(3+v) \rho}{4}\left(\frac{\pi n}{30}\right)^{2}\left[R_{e d}^{2}+R_{e}^{2}\left(\frac{1-v}{3+v}\right)\right] .
$$

2.2.2. Basic Geometric Quantities after Deformation. Based on the above deformations, the essential length geometric quantities of the logarithmic sprag clutch have corresponding changes and can be expressed as 


$$
\begin{aligned}
& O A=R_{i}-\delta_{B I}-\frac{\delta_{H I}}{2} \\
& O B=R_{e}+\delta_{B E}+\frac{\delta_{H E}}{2}+\delta_{c e} \\
& O C_{e}=R_{e}-r_{e}+\delta_{B E}+\frac{\delta_{g}}{2}+\delta_{H E} .
\end{aligned}
$$

As shown in Figure 4 , the angles $\angle O C_{g} C_{e}, \beta, \nu, \gamma$, and $\eta$ and the parameters of the logarithmic inner profile vary with the changes of the lines $O A, O B$, and $O C_{e}$. The equations of these parameters can be expressed as

$$
\begin{aligned}
\angle O C_{g} C_{e} & =\theta_{i}+\alpha=\arccos \left(\frac{C_{e} C_{g}^{2}+O C_{g}^{2}-O C_{e}^{2}}{2 \times C_{e} C_{g} \times O C_{g}}\right), \\
\beta & =\arctan (m)-\arcsin \left(\frac{m \times O A}{O C_{e} \times \operatorname{sqrt}\left(1+m^{2}\right)}\right), \\
\nu & =-\arctan \left(\frac{O B \times \sin (\beta)}{O A-O B \times \cos (\beta)}\right), \\
\eta & =\arcsin \left(\frac{m \times O A}{O C_{e} \times \operatorname{sqrt}\left(1+m^{2}\right)}\right), \\
\rho & =\frac{O A \times \sin (\beta)}{\sin (\eta)} \\
\text { theta } & =\log \frac{(\rho / a)}{m},
\end{aligned}
$$

where $\theta_{i}$ is the initial value of the angle $\angle O C_{G} C_{i}$ at the initial contact position, $\alpha$ is the rotation angle of the sprag roller, and $O C_{g}$ is also the variable parameter depending on the deformations.

2.2.3. Calculation of the Normal Contact Force. Based on the above equations of geometric deformation coordination, the normal contact force on the inner race would be obtained through nonlinear iterations and can be expressed as

$$
N_{b i}= \begin{cases}f\left(\alpha, \theta_{i}, R_{i}, R_{e}, r_{e}, \rho, a, m, \delta_{h e}, \delta_{h i}, \delta_{b e}, \delta_{b i}, \delta_{g}, \delta_{c e}\right), & \alpha<0, \\ 0, & \text { else. }\end{cases}
$$

Note that the contact angles $v$ and $\omega$ are so small that the values of normal forces on the inner and outer races are approximately equal.

2.2.4. Calculation of the Friction Force. Since the friction at the contacts is static friction for most of the time during the engagement, the alternate friction model including static friction, rate-dependent friction, and the transformation between them is adapted to reflect the sliding in contacts. In the model, a narrow band of zero velocity [17] is introduced to overcome the discontinuity of the transition point. Figure 6 shows the alternate friction model [18] of the inner contact, which is similar to the contact friction model of the outer contact. Its expression can be written as

$$
T_{b i}(x)= \begin{cases}T_{b i f}(x), & \text { if }\left|\operatorname{Vel}_{b i}\right|<D_{V},\left|T_{b i f}(x)\right|<T_{b i s} \text { (stick), } \\ T_{b i s} \operatorname{sgn}\left(T_{b i f}(x)\right), & \text { if }\left|\operatorname{Vel}_{b i}\right|<D_{V},\left|T_{b i f}(x)\right|>T_{b i s} \text { (stick to slip transition), } \\ N_{b i} \mu_{b d}\left(\operatorname{Vel}_{b i}\right) \operatorname{sgn}\left(\operatorname{Vel}_{b i}\right), & \text { if }\left|\operatorname{Vel}_{b i}\right|>D_{V} \text { (slip), }\end{cases}
$$

with

$$
\mu_{b d}\left(\operatorname{Vel}_{b i}\right)=\mu_{c b}+\left(\mu_{s b}-\mu_{c b}\right) e^{-\gamma_{b}\left|\operatorname{Vel}_{b i}\right|}
$$

where $x$ is the system state vector, $\mathrm{Vel}_{b i}$ is the sliding velocity at the contact point of the inner race, $D_{V}$ is a narrow band of zero velocity, $T_{b i f}(x)$ is the static force to keep the pure rolling contact, and $T_{b i s}$ is the maximum static friction force. $\mu_{b d}$ is used to represent the dynamic friction coefficient during the slip phase since the contacts between the sprag roller and the races are cylindrical contact with high contact pressure and lubrication. In the expression, $\mu_{s b}$ and $\mu_{c b}$ are the static and Coulomb friction coefficients with $0<\mu_{c b}<\mu_{s b}<1$ and $\gamma_{b}$ is a positive constant. These parameters can be calculated by fitting the dynamic friction coefficient as a function of relative sliding speed, which is obtained from a disc machine using rolling cylinders as reported in Johnson's article [19].
2.3. Differential Equations of Motion. Based on Newton's second law, the differential equations of the motion of the logarithmic sprag clutch can be derived to describe the dynamic behavior during the engagement. First, it is necessary to analyze the forces acting on the components of the logarithmic sprag clutch: the sprag roller, the inner race, and the outer race.

The forces acting on the sprag roller are shown in Figure 7. $N_{b i}$ and $N_{b e}$ are the normal forces at the contacts of the inner race and outer race, $T_{b i}$ and $T_{b e}$ are the friction forces at the contacts of the inner race and outer race, $C_{r l}$ is the torsional viscous damping between the races, $C_{b i}$ and $C_{b e}$ are the constant torques applied on the inner and outer races, $K_{r}$ is the stiffness of the elastic blades holding the sprag rollers and the races in contact, $\alpha_{\max }$ is the maximum rotation angle depending on the logarithmic curve of the sprag roller, and $K_{r}$ and $\alpha_{\max }$ are obtained from the initial contact equilibrium equations.

The application of Newton's second law yields, for the sprag rollers, 


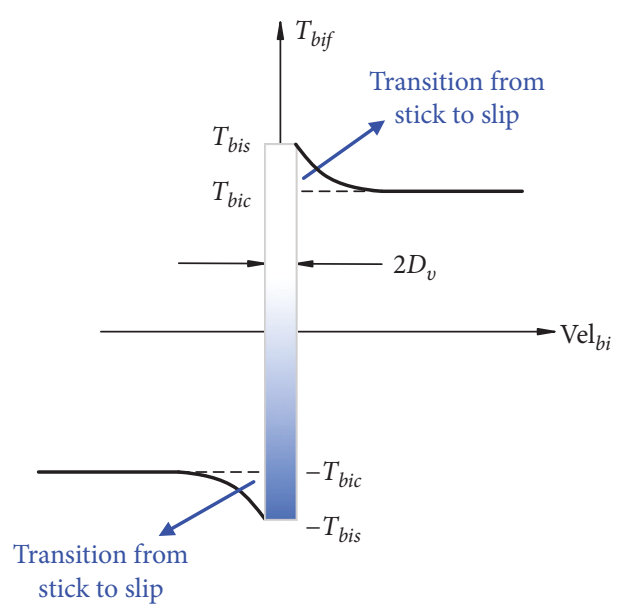

Figure 6: Alternate friction model considering static and ratedependent friction.

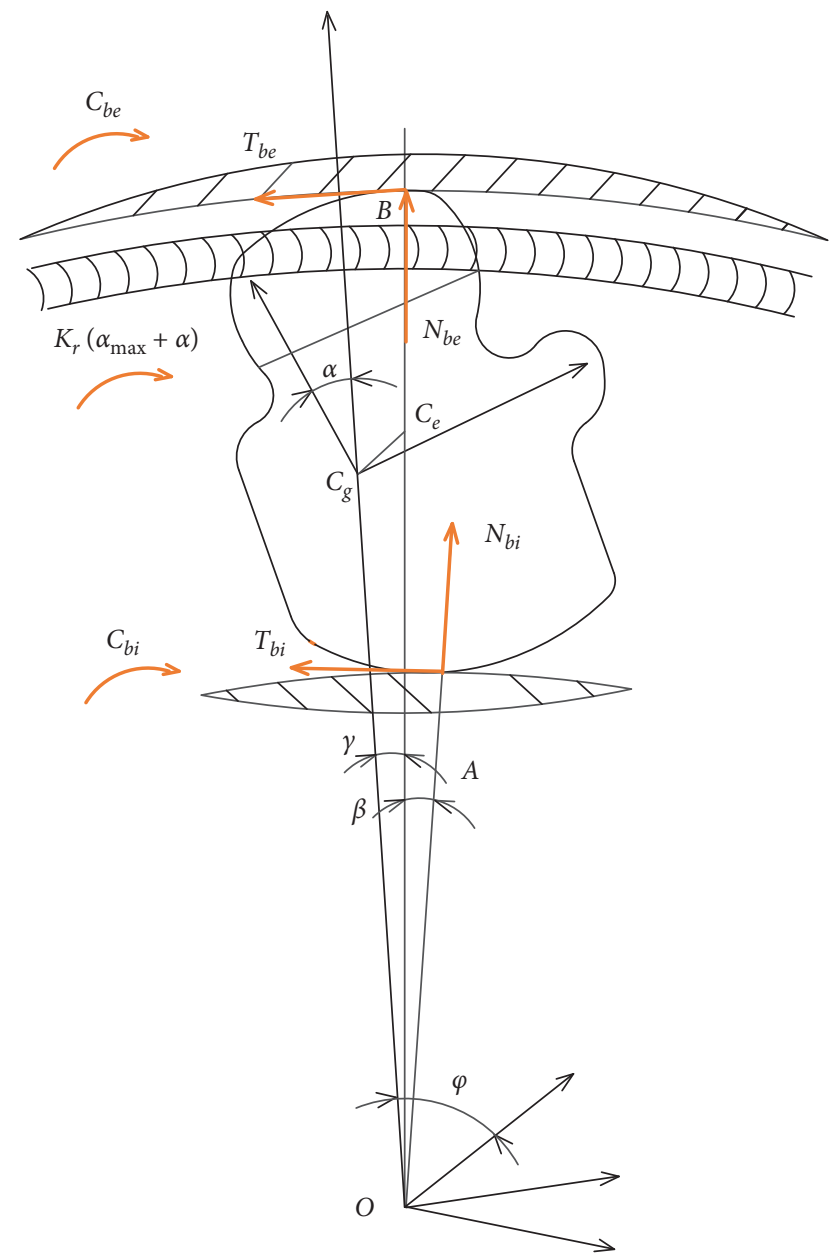

Figure 7: A schematic diagram of forces on the sprag roller.

$$
\begin{aligned}
I_{g}(\ddot{\alpha}+\ddot{\varphi})-b_{e} T_{b e}-K_{r}\left(\alpha+\alpha_{\max }\right)-b_{i} T_{b i} \\
+h_{i} N_{b i}-h_{e} N_{b e}=0, \\
-m g O C_{g} \ddot{\varphi}-\cos (\beta+\gamma) T_{b i}+\sin (\beta+\gamma) N_{b i} \\
+T_{b e} \cos (\gamma)-N_{b e} \sin \gamma=0,
\end{aligned}
$$

with

$$
\begin{aligned}
b_{i} & =O C_{g} \cdot \cos (\beta+\gamma)-O A, \\
b_{e} & =O B-O C_{g} * \cos (\gamma), \\
h & =O C_{g} \cdot \sin (\beta+\gamma), \\
h_{e} & =O C_{g} \cdot \sin (\gamma),
\end{aligned}
$$

where $I_{g}$ is the inertia of the sprag roller, $I_{b i}$ and $I_{b e}$ are the inertia of the inner race and outer races, respectively, $\varphi$ and $\alpha$ are the two degrees of the sprag roller, $\varphi$ is the azimuthal angle between the azimuth coordinate system $\overrightarrow{o x_{G} y_{G}}$ and the absolute coordinate system $\overrightarrow{o x_{o} y_{o}}$, and $\alpha$ is the rotational angle of the sprag roller between the body fitted coordinate system $\overrightarrow{o x_{g} y_{g}}$ and the azimuth coordinate system $\overrightarrow{o x_{G} y_{G}}$.

For the inner and outer races,

$$
\begin{aligned}
& I_{b i} \ddot{\theta}_{b i}-n_{s} T_{b i}\left(\frac{R_{i}-\delta_{B I}-\delta_{H I}}{2}\right)+C_{r l}\left(\dot{\theta}_{b i}-\dot{\theta}_{b e}\right) \\
& -C_{b i}=0, \\
& I_{b e} \ddot{\theta}_{b e}+C_{r l}\left(\dot{\theta}_{b e}-\dot{\theta}_{b i}\right)+n_{s} T_{b e}\left(\frac{R_{e}+\delta_{B E}+\delta_{H E}}{2}+\delta_{c e}\right) \\
& \quad-C_{b e}=0,
\end{aligned}
$$

where $\theta_{b i}$ and $\theta_{b e}$ are the degrees of the inner and outer races, respectively.

The system equations of motion are nonlinear ordinary second order differential equations. They can be solved using a fourth-order Runge-Kutta algorithm with a fixed time step. The time step for the numerical procedure is chosen to be $\Delta_{t}=1 \times 10^{-5} \mathrm{~s}$.

2.4. Validation. To verify the effectiveness of the proposed model, the comparison analysis of dynamic contact forces from different models is performed under the same operating condition and structural parameters of the logarithmic sprag clutch. The operating condition is that the inner race accelerates and moves into the engagement direction due to the applied torsional torque $T_{1}$, while the outer race is connected to a fixed interface through a spring with large torsional stiffness [6]. The parameters of the logarithmic sprag clutch are shown in Table 1.

Figure 8 shows the comparison of dynamic contact forces on the sprag rollers obtained from the proposed model, the results of LS/DYNA, and Liu's model. During the engaging process, the dynamic contact force causes local contact deformations and structural deformations of the races. In Liu's model, structural deformations of the inner and outer races are not considered in the calculation of the dynamic contact force, but these deformations are large enough to be ignored [5]. Due to this reason, the maximum dynamic contact force is significantly greater than the one from the proposed model and the LS/DYNA model, which have considered the above two deformations by the finite 
TABLE 1: The parameters of the sprag clutch applied in the simulation.

\begin{tabular}{lccc}
\hline Parameter & Value & Parameter & Value \\
\hline$n b g$ & 12 & $m_{g}(\mathrm{~kg})$ & $1.8 \times 10^{-3}$ \\
$R_{i d}(\mathrm{~mm})$ & 7.21 & $I_{1}\left(\mathrm{~kg} \cdot \mathrm{m}^{2}\right)$ & $1.97 \times 10^{-4}$ \\
$R_{i}(\mathrm{~mm})$ & 11.11 & $I_{b i}\left(\mathrm{~kg} \cdot \mathrm{m}^{2}\right)$ & $1.41 \times 10^{-3}$ \\
$R_{e}(\mathrm{~mm})$ & 19.44 & $I_{b e}\left(\mathrm{~kg} \cdot \mathrm{m}^{2}\right)$ & $1.41 \times 10^{-3}$ \\
$R_{e d}(\mathrm{~mm})$ & 26.23 & $I_{g}\left(\mathrm{~kg} \cdot \mathrm{m}^{2}\right)$ & $1.18 \times 10^{-8}$ \\
$r_{i 1}(\mathrm{~mm})$ & 4.02 & $K_{r}(\mathrm{Nm} / \mathrm{rad})$ & 0.01 \\
$r_{i 2}(\mathrm{~mm})$ & 4.02 & $C_{r l}(\mathrm{Nms} / \mathrm{rad})$ & 0.1 \\
$r_{i 3}(\mathrm{~mm})$ & 4.02 & $C_{f}(\mathrm{Nm})$ & $1.66 \times 10^{-2}$ \\
\hline
\end{tabular}

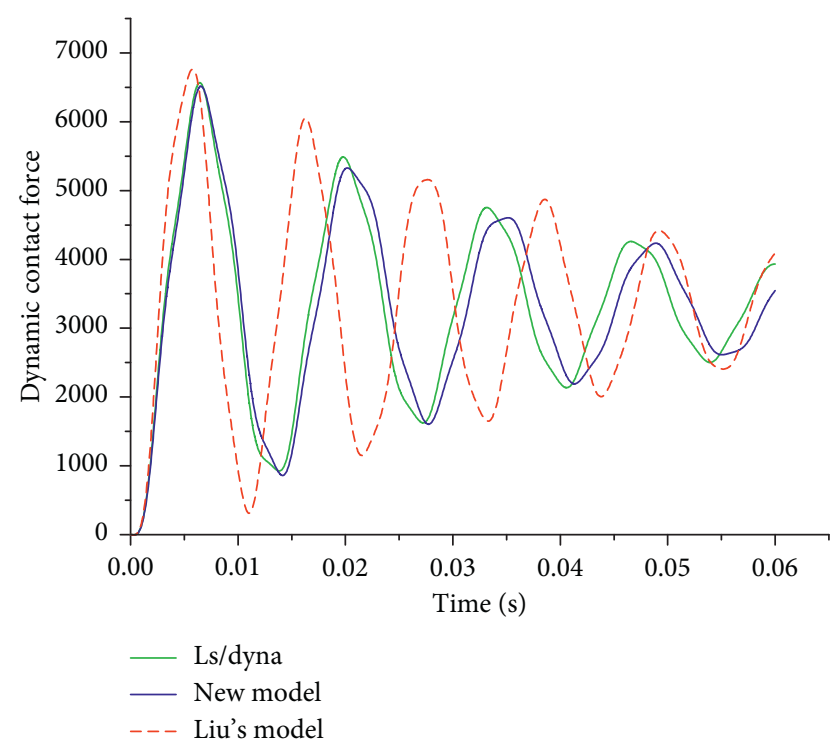

Figure 8: Comparison of the dynamic contact force obtained from different models.

element method. On the other hand, the nonlinearity of stiffness is more important than the nonlinear damping on the dynamic behavior of the sprag clutch. Thus, the same damping obtained from Vernay's experiment $[6,7]$ is applied in both the proposed model and the LS/DYNA model. Therefore, except the similar amplitude, the shape of the dynamic contact force from the proposed model is also similar to the one from the LS/DYNA.

In general, the amplitude and shape of dynamic contact force obtained from the present model agree better with the results of LS/DYNA than Liu's model. This good agreement shows the effectiveness of the proposed model.

\section{Kriging-Based Optimization of Design Parameters}

The single optimization objective function is minimized $\mathrm{Pre}_{\max }$ throughout the engagement:

$$
\min [f(\mathbf{X})]=\min \left[\operatorname{Pre}_{\max }\right],
$$

where $\mathbf{X}$ is the design variable vector, $f(\mathbf{X})$ represents the objective function, and $\mathrm{Pre}_{\max }$ is the maximum contact stress throughout the engagement.
Assuming that the basic geometric parameters of the sprag clutch have been chosen, the three design parameters of the sprag clutch profile are chosen as design variables for the optimization:

$$
\mathbf{X}=\left\{k_{1}, k_{2}, k_{3}\right\} .
$$

To reduce the solution range, the strict upper and lower bounds of the design parameters are given as follows:

$$
\begin{aligned}
1 & \leq K_{1} \leq 5, \\
0.4 & \leq K_{2} \leq 0.7, \\
0.005 & \leq z_{m} \leq 0.025 .
\end{aligned}
$$

Based on the new analytical model, the objective function value in the optimization can be obtained through dynamic simulation. However, the optimization process involves computationally intensive dynamic simulations, which are quite inefficient due to the nonlinear iterations in the new model. Therefore, a more efficient prediction model is necessarily developed to estimate the value of the objective function for any given point in the design space.

Figure 9 presents a procedure for kriging-based optimization design of modification parameters, and it is divided into three main parts: experimental design, kriging modeling, and genetic algorithm optimization.

First, a full factorial design is adapted to obtain the sampled points of the design parameters. Each design parameter is divided into five levels in its design range, and the design points selected are shown in Figure 10.

Then, based on the sampled points and corresponding calculated maximum contact pressure during the engagement, a kriging model [20] is established to reflect the function relationship between them and is written as

$$
Y(\mathbf{x})=Q(\mathbf{x})+G(\mathbf{x})
$$

where $\mathbf{x}$ is the input vector for any set of profile modification parameters in design space, $Y(\mathbf{x})$ is the actual unknown function relationship between the maximum contact pressure and profile modification parameters, $Q(\mathbf{x})$ is the quadratic polynomial function of $\mathbf{x}$, and $G(\mathbf{x})$ is the realization of a Gaussian stochastic process [21].

Ten additional sampled points from design space are randomly selected to verify the kriging model, and the results are shown in Table 2. It can be seen that all the relative errors and MSE of the sampled points are within the allowable range [20,21], and the results show the effectiveness of the kriging model.

At the last, the genetic algorithm is used as an optimization design algorithm. Initial population size is set as 500 , and the number of generations is set as 100 , crossover probability is 0.9 , and mutation probability is 0.01 .

\section{Results and Discussion}

In this section, based on the proposed analytical model and kriging-based optimization process, the effect of design parameters on contact pressure distribution is investigated, and design parameters under different applied torques are optimized. To achieve these, it is necessary to define the 


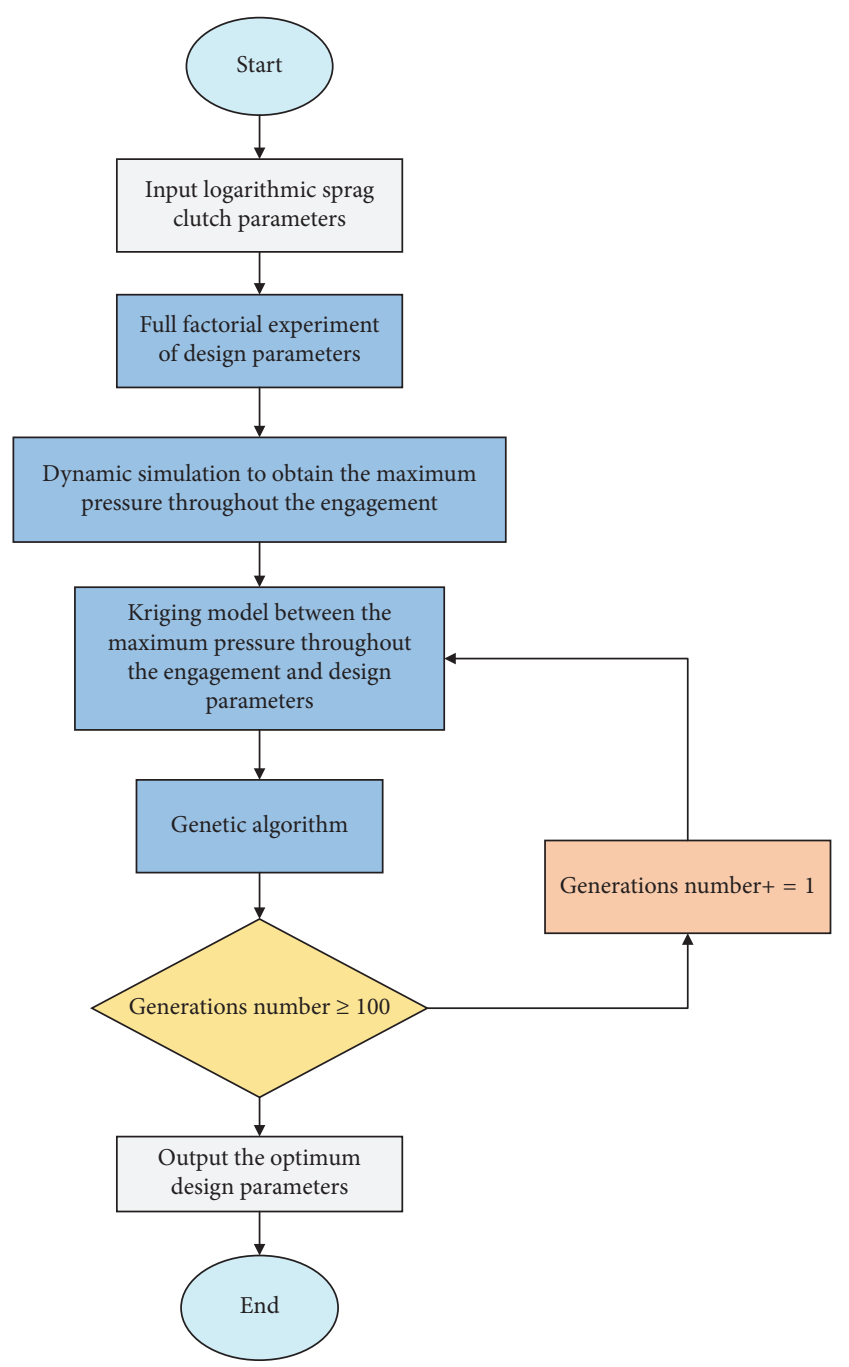

FIGURE 9: The procedure of optimization for design parameters based on the kriging model.

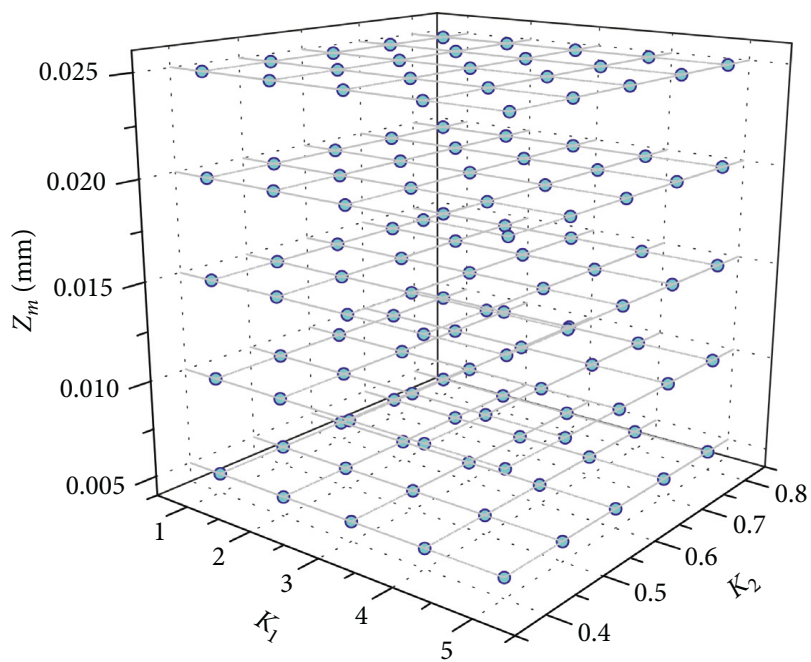

Figure 10: The sampled points obtained by the full factorial design.
TABLE 2: Ten additional selected points and calculated results to verify the kriging model.

\begin{tabular}{lccc}
\hline $\begin{array}{l}\text { Actual } \\
\text { value }(\mathrm{Mpa})\end{array}$ & $\begin{array}{c}\text { Predictive } \\
\text { value }(\mathrm{MPa})\end{array}$ & $\begin{array}{c}\text { Relative } \\
\text { error }\end{array}$ & MSE \\
\hline 3124.2 & 3167.9 & 1.38 & 14.08 \\
3000.0 & 3050.1 & 1.64 & 10.86 \\
3002.4 & 3015.9 & 0.45 & 1.36 \\
2994 & 2994 & 0 & 0 \\
3011.3 & 3001.3 & 0.33 & 3.55 \\
3080.3 & 3084.7 & 0.14 & 5.3 \\
3038.1 & 3047.3 & 0.3 & 5.15 \\
3027.1 & 3044.5 & 0.57 & 15.79 \\
3038.2 & 3032.5 & 0.19 & 3.01 \\
3079.2 & 3073.8 & 0.17 & 3.01 \\
\hline
\end{tabular}

structural parameters and operating conditions for analysis and optimization. The structural parameters of the logarithmic sprag clutch are listed in Table 1, and the centroid position coordinates are automatically obtained through the CAD model of the clutch using macro programming method. The operating condition is defined as follows: with the outer race connected to a fixed interface through a spring with large torsional stiffness, a constant torque $C_{e 1}$ is applied on the inner race. In addition, for optimizing the design parameters under different torques, $C_{e 1}$ are respectively assigned to $25 \mathrm{~N} \cdot \mathrm{m}$ and $40 \mathrm{~N} \cdot \mathrm{m}$ to investigate the effect of torque applied on the optimum results of design parameters.

\subsection{Effect of Design Parameters of Roller on Contact Pressure} Distribution. At any position during the engaging process, the contact stress between the sprag roller and the inner race is greater than that between the sprag roller and the outer race, and the results still remain the same even when the sprag roller is profiled. Therefore, the effect of design parameters on contact pressure distribution of the inner contact is chosen to be investigated.

To investigate the effect of design parameters on contact pressure distribution, the effect of design parameters on the logarithmic profile should be firstly investigated. Figure 11 shows the logarithmic profiles of the sprag roller under different design parameters. When only $K_{1}$ increases, the shape of the logarithmic profile becomes significantly steep, and the overall crowned data increase. And when only $K_{2}$ decreases, the shape becomes weakly steep with the starting point moving to the end, but the more obvious is the expansion of the central straight region. Compared to $K_{1}, K_{2}$, and $z_{m}$ play a major role in determining the overall crowned data, especially the crowned data of the end. It can be concluded that the shape and crowned data of the logarithmic profile depend on all the three parameters, of which $K_{1}$ mainly determine the shape and $z_{m}$ mainly determine the overall crowned data. As for the length of the central straight region, it is only determined by $z_{m}$.

Figure 12 shows the contact distribution under different design parameters. Although the edge effect in all contact distributions has been significantly weakened in contrast to no profile modification, the uniformity of each pressure distribution is still different. As the load area is determined by the 


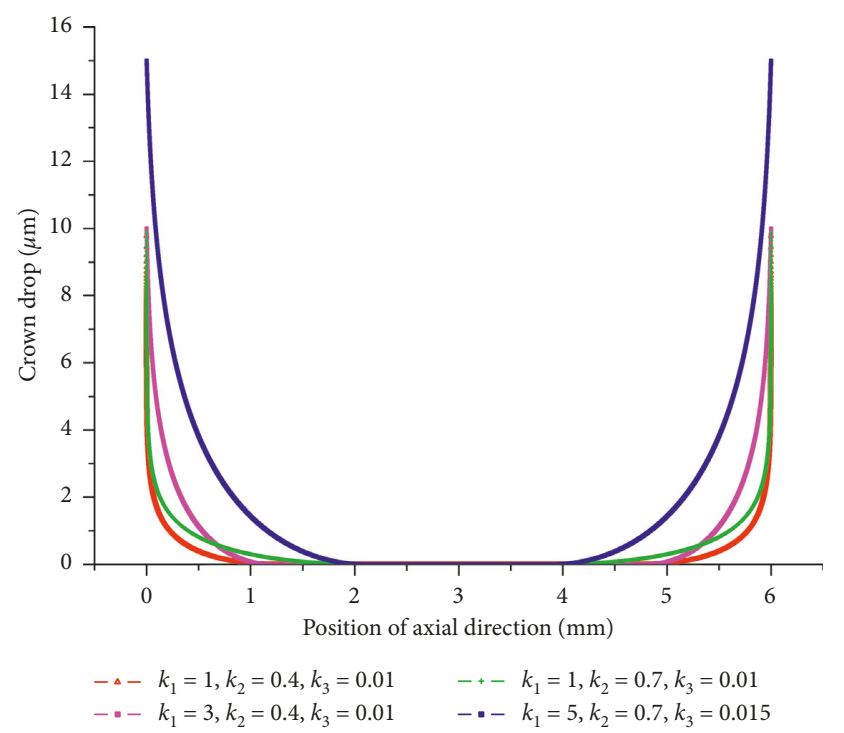

FIGURE 11: Logarithmic profile curves of the roller under different design parameters.

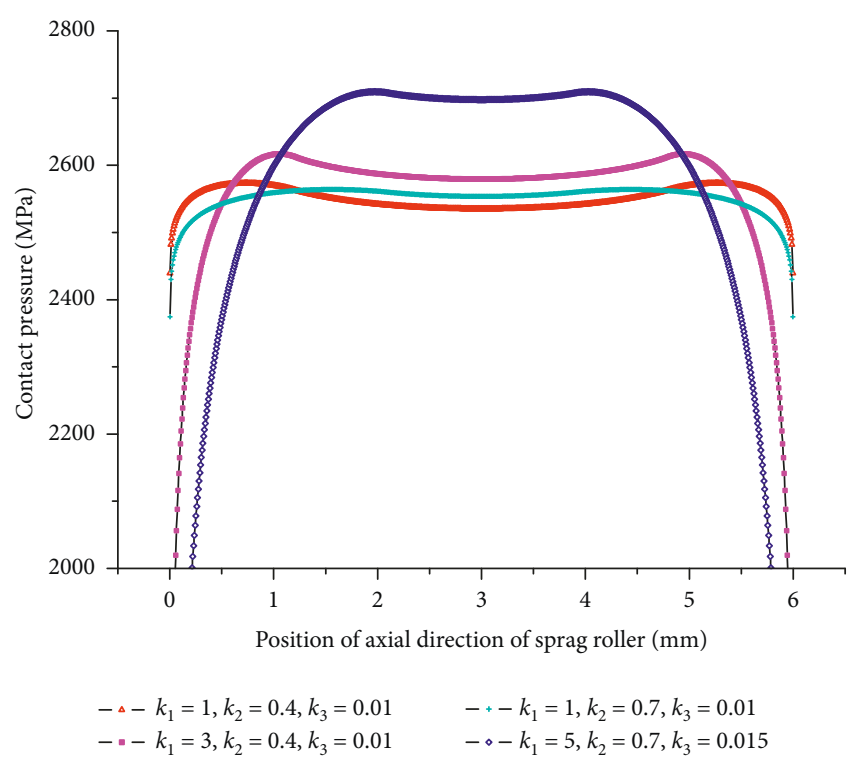

FIGURE 12: Contact pressure distribution under different design parameters.

uniformity of pressure distribution, the better uniformity means the lower value of the maximum stress, which is defined as $p_{\max }$ in this paper. When $K_{1}, K_{2}$, and $z_{m}$ are assigned to $1,0.7$, and 0.01 , the uniformity of pressure distribution is the best, and $p_{\max }$ is thus the lowest. However, when $K_{1}, K_{2}$, and $z_{m}$ deviate from these values, the results deteriorate, and the extent of the deterioration is directly related to the degree of deviation. The farthest deviation of $K_{1}, K_{2}$, and $z_{m}$ assigned to $5,0.7$, and 0.015 shows the most uneven pressure distribution and the highest $p_{\max }$ among the combinations.

Figure 13 shows the contact distribution throughout the engagement under two sets of design parameters. It can be seen that the contact pressure distribution at different moments shows different characteristics, although the

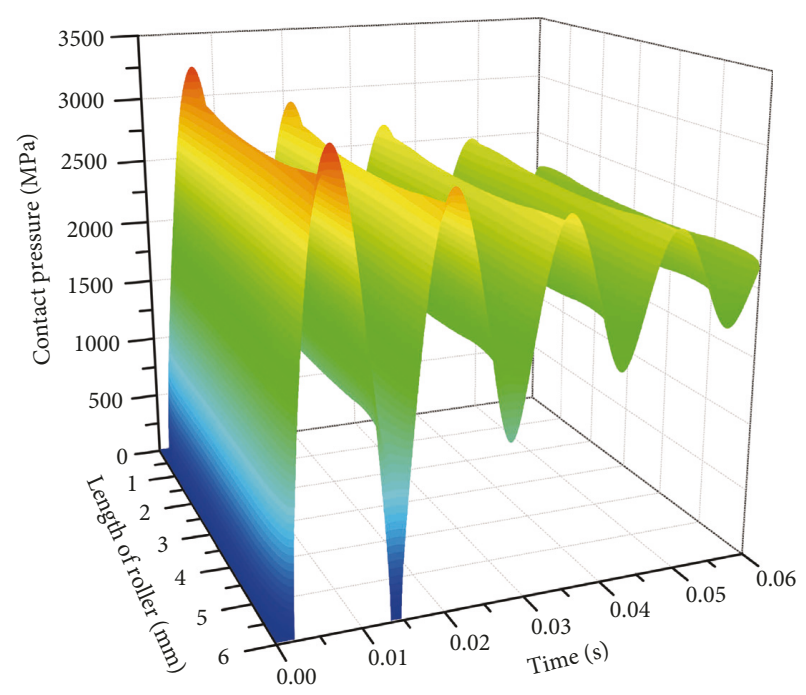

(a)

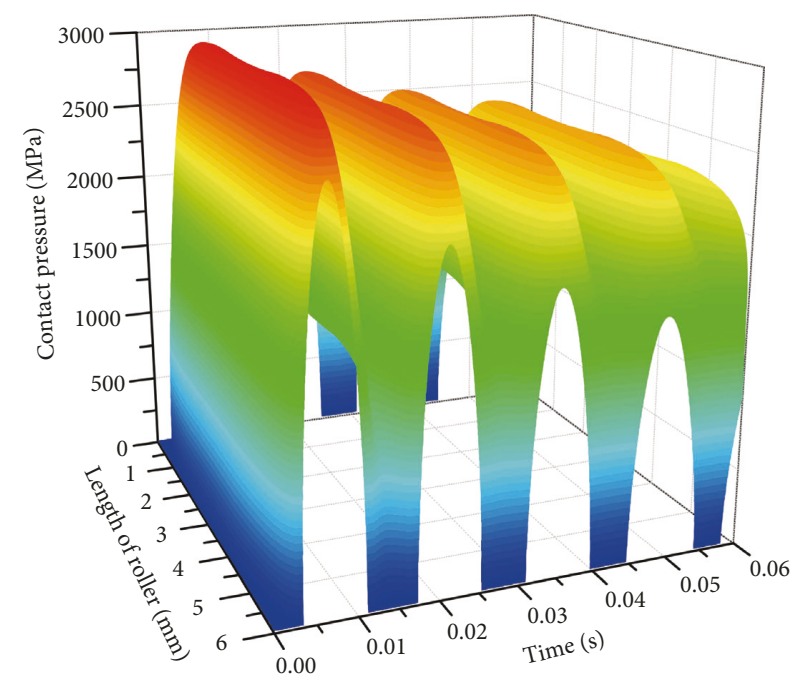

(b)

FIgURE 13: The contact pressure distribution throughout engagement varies with different design parameters under applied torque $25 \mathrm{~N} \cdot \mathrm{m}$. (a) $K_{1}=1, K_{2}=0: 4, z_{m}=0.01$, and (b) $K_{1}=3, K_{2}=0: 4, z_{m}=0.01$.

design parameters are the same. At the initial moment of engaging, the pressure is only distributed at the two ends of the sprag roller. At the first peak, it shows the characteristics of high at both ends and low in the middle. However, it reflects the opposite distribution feature at the first trough. In addition, with increasing end crowned data $z_{m}$ in the figure, the uniformity of pressure distribution at peaks in the figure has clear improvement and the maximum stress $p_{\max }$ has been significantly reduced.

Note that the maximum stress $p_{\max }$ at the first peak is the maximum stress throughout the engagement Pre $_{\max }$. Especially, it can be reduced together with the uniformity of the contact distribution by optimizing the three design parameters.

4.2. Optimization. Figure 14 shows the maximum contact stress changing with the applied torque and design 


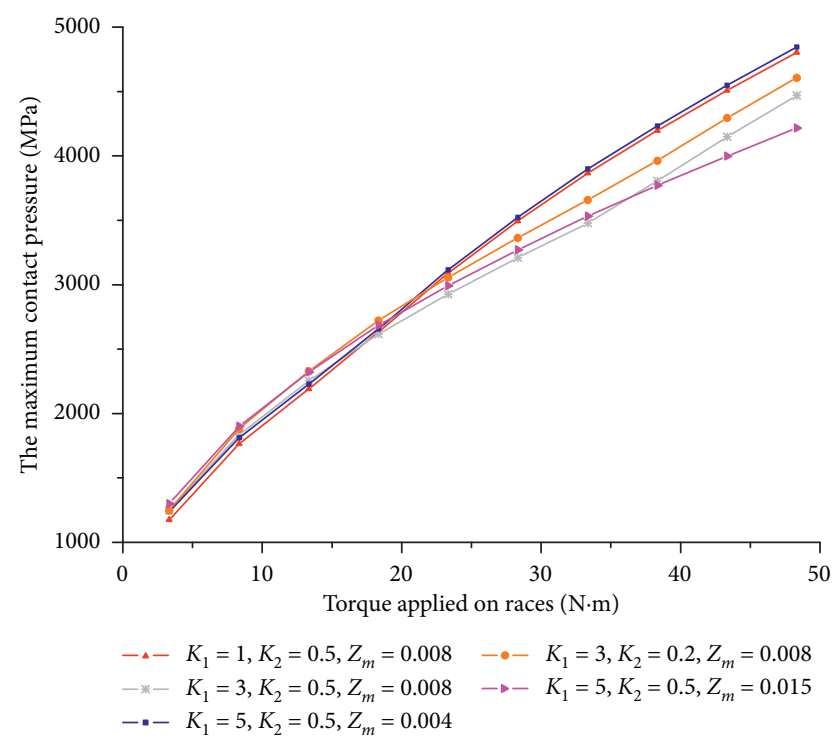

FIGURE 14: The maximum contact pressure changes with load and design parameters.

parameters. With the change of design parameters under a specific torque applied, the maximum contact stress varies in a region, and the low limit of the regions for different torques is formed by different combinations of design parameters. When the torque applied is $10 \mathrm{~N} \cdot \mathrm{m}$, the low limit of the region is formed by $K_{1}, K_{2}$, and $z_{m}$ assigned to $1,0.5$, and 0.008 , respectively. And when the torque applied is $30 \mathrm{~N} \cdot \mathrm{m}$, the low limit of region is formed by $K_{1}$, $K_{2}$, and $z_{m}$ assigned to $5,0.5$, and 0.015 , respectively. The reason for this is that $K_{1}$ and $z_{m}$ should also increase with the increasing torque applied to obtain a uniform pressure distribution and the resulting low limit of the maximum contact stress.

From the above analysis, it can be concluded that the maximum contact pressure can be clearly reduced by optimizing $K_{1}, K_{2}$, and $z_{m}$, and the optimization of the three design parameters should be performed under a specific applied torque.

4.2.1. Case Torque Applied Is $25 \mathrm{~N} \cdot \mathrm{m}$. Figure 15 gives that the maximum contact pressure throughout the engagement Pre $_{\max }$ varies with design parameters under the applied torque $25 \mathrm{~N} \cdot \mathrm{m}$. Figure 15(a) shows that $\mathrm{Pre}_{\max }$ decreases first and then turns to increase with the increasing $K_{1}$ or $K_{2}$. Firstly, the decrease in Pre $_{\max }$ means the contact pressure is gradually evenly distributed; it is because the edge pressure gradually decreases and the middle contact pressure increases as $K_{1}$ or $K_{2}$ increases. Then Pre max $_{\text {marns to increase }}$ with further increase in $K_{1}$ or $K_{2}$, meaning that the improved uniformity of the contact pressure distribution begins to deteriorate. The reason for this is that the edge pressure has been reduced so much that the middle contact pressure starts to rise. As shown in Figure 15(b), Pre ${ }_{\max }$ has similar trends with the increasing $z_{m}$ or $K_{1}$, decreasing first and then turns to increase, and the reason for the trend is also the same.

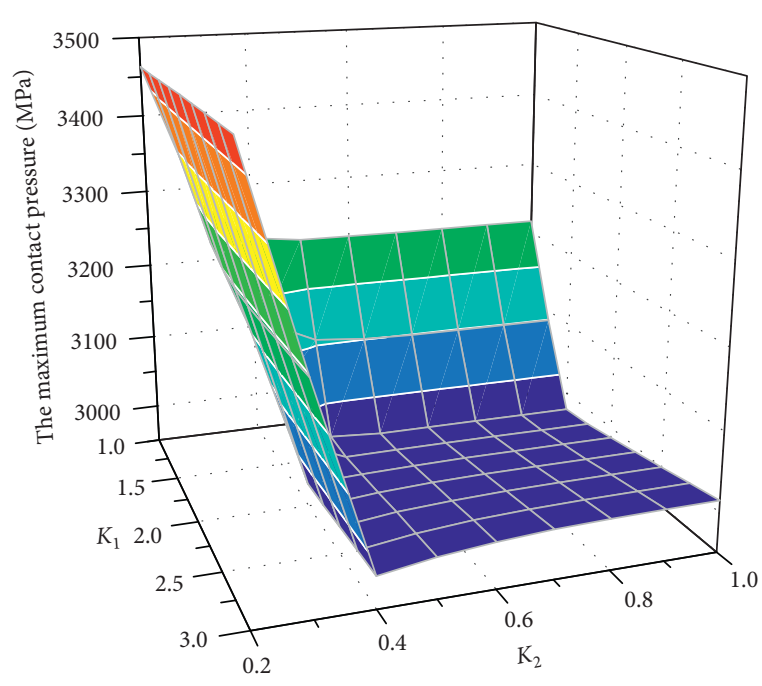

(a)

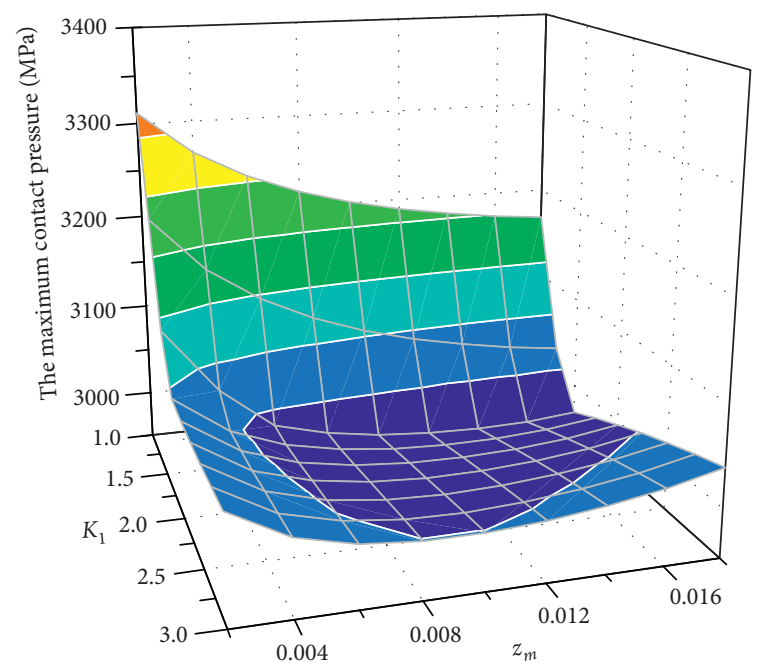

(b)

FIgURE 15: The maximum contact pressure distribution throughout engagement varies with design parameters under the applied torque $25 \mathrm{~N} \cdot \mathrm{m}$. (a) $z_{m}=0.01$ and (b) $K_{2}=0.5$.

As a result of the optimization based on the genetic algorithm method, the optimum design parameters under the applied torque are obtained as shown below,

$$
\begin{aligned}
& K_{1}=2.1507, \\
& K_{2}=0.6763, \\
& z_{m}=0.0121 .
\end{aligned}
$$

Using the optimum logarithmic profile, the comparison of contact pressure distribution between the unmodified profile and the optimized profile is shown in Figure 16. In Figure 16(a), sharp edge stress occurs at both ends of the roller with the unmodified profile, and the maximum contact pressure throughout the engagement is close to $3500 \mathrm{MPa}$. In Figure 16(b), the contact pressure distribution at the first peak is almost uniform along the contact length direction, and thus the maximum contact pressure throughout the engagement is 


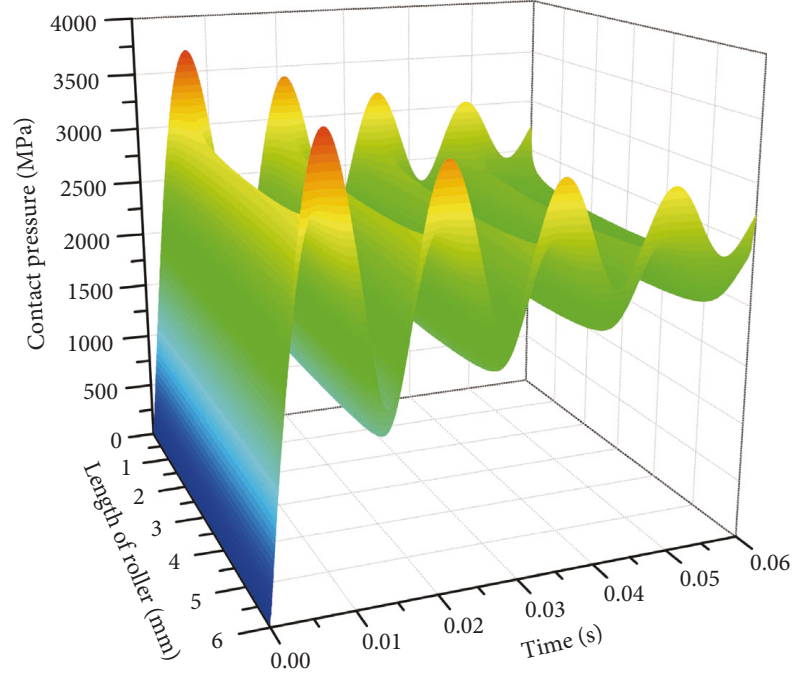

(a)

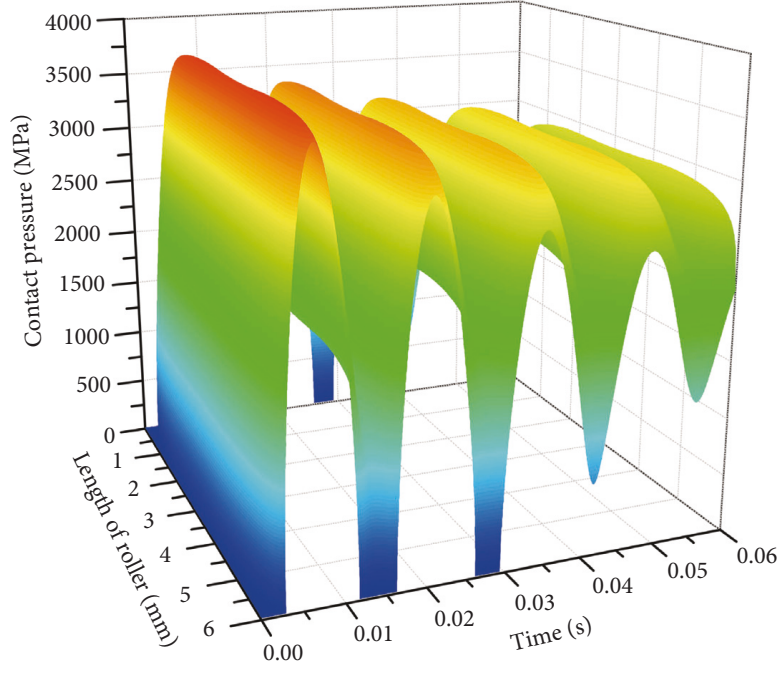

(b)

FIGURE 16: The contact pressure distribution throughout engagement under the applied torque of $25 \mathrm{~N} \cdot \mathrm{m}$ (a) before optimization and (b) after optimization.

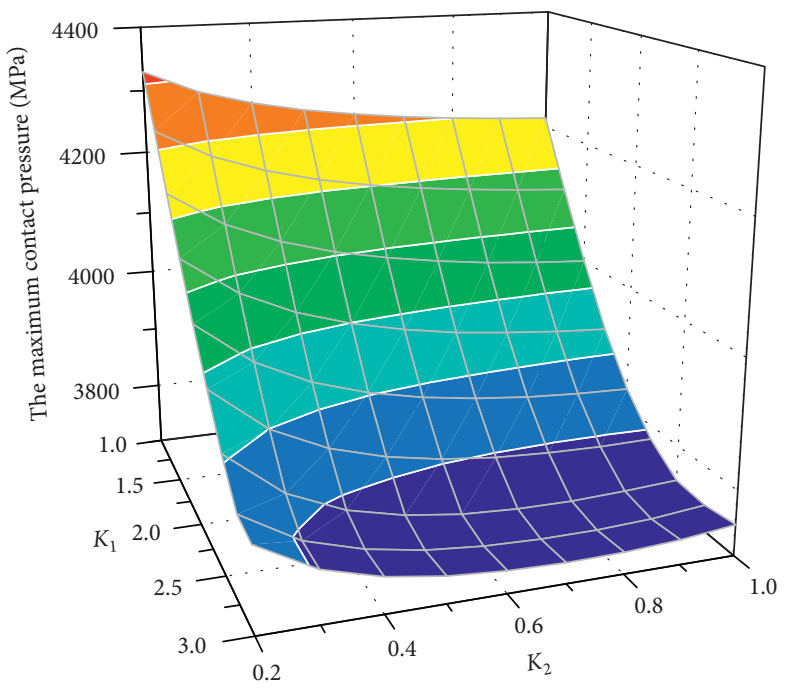

(a)

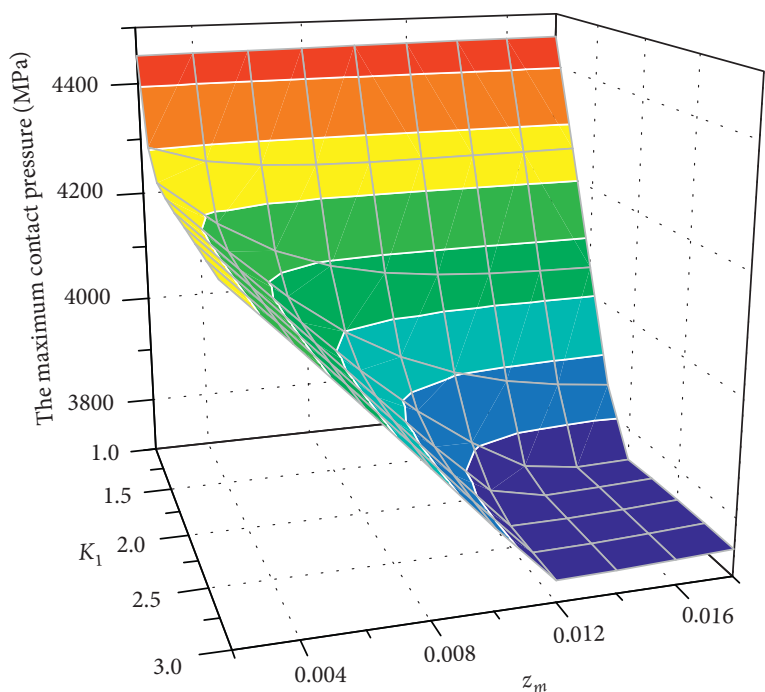

(b)

FIGURE 17: The maximum contact pressure distribution throughout engagement varies with design parameters under the applied torque of $40 \mathrm{~N} \cdot \mathrm{m}$. (a) $z_{m}=0.01$ and (b) $K_{2}=0.5$.

reduced to $2980 \mathrm{MPa}$, which decreases by 14.86 per cent compared with the result of the unmodified profile.

4.2.2. Case Torque Applied Is $40 \mathrm{~N} \cdot \mathrm{m}$. Figure 17 shows that the maximum contact stress throughout the engagement $\mathrm{Pre}_{\max }$ varies with design parameters under the applied torque $40 \mathrm{~N} \cdot \mathrm{m}$. Compared with the results of applied torque $25 \mathrm{Nm}$, the design parameter $K_{1}$ is necessary to increase significantly to reduce Pre $\operatorname{Pax}_{\max }$, and the effect of $z_{m}$ is more obvious.

The optimum design parameters under the applied torque are obtained as shown below,

$$
\begin{aligned}
& K_{1}=2.80 \\
& K_{2}=0.7 \\
& z_{m}=0.0118
\end{aligned}
$$

Using the optimum logarithmic profile, the comparison of contact pressure distribution between the unmodified profile and the optimized profile is shown in Figure 18. $\mathrm{Pre}_{\max }$ decreases from $4700 \mathrm{MPa}$ to $3400 \mathrm{MPa}$, which is a 27.86 percent drop compared with the result of the unmodified profile, and thus the improvement range increases with the increasing torque applied. 


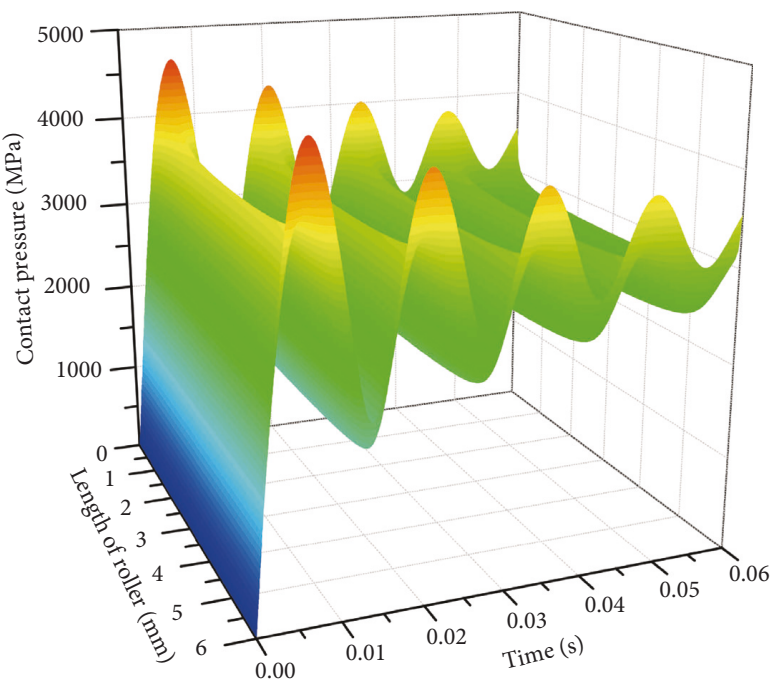

(a)

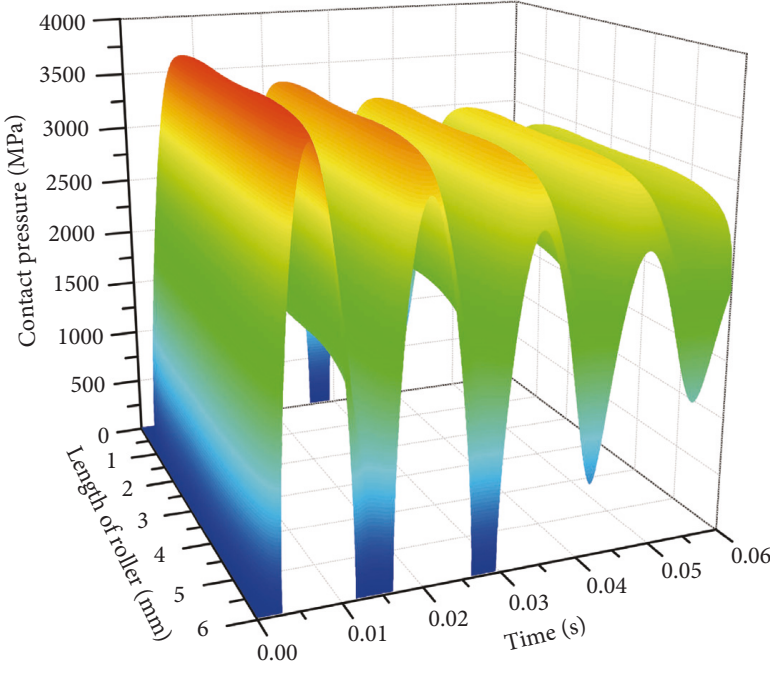

(b)

Figure 18: The contact pressure distribution throughout engagement under the applied torque $40 \mathrm{~N} \cdot \mathrm{m}$ (a) before optimization and (b) after optimization.

\section{Conclusion}

In the present paper, an analytical model of a logarithmic sprag clutch considering profile modification has been proposed, and then kriging-based optimization of design parameters has been performed to reduce the maximum contact pressure throughout the engagement. The following conclusions can be drawn from the work presented in this paper:

(1) To improve the accuracy of the model for the logarithmic sprag clutch, a new analytical model considering profile modification, structural deformation of races, and friction between sprag rollers and the inner race has been presented. Based on the new model, the calculated dynamic normal force has better agreement with LS/DYNA results than the previous model, and contact pressure distribution throughout the engagement reveals the effect of profile design parameters.

(2) The design parameters significantly affect the contact pressure distribution by changing the shape of the logarithmic profile, the overall crowned data, and the length of the central straight region. Using the selected appropriate design parameters, the uniform contact distribution and thus the greatly reduced maximum stress at each moment of engagement can be obtained. Furthermore, the maximum contact pressure throughout the engagement is located on the first peak of the contact pressure distribution throughout the engagement.

(3) The kriging-based optimization using the genetic algorithm is proven to be an effective and timesaving method for optimizing the three design parameters. By using the optimal design parameters of the logarithmic profile, the maximum stress throughout the engagement can be greatly reduced. Under different applied torques, the design parameters should be optimized differently.

\section{Data Availability}

The data used and analysed to support the findings of this study are available from both the first author and the corresponding author upon request.

\section{Conflicts of Interest}

The authors declare that they have no conflicts of interest.

\section{Acknowledgments}

This work was supported by the National Natural Science Foundation of China (Grant No. 51505100).

\section{References}

[1] P. Lynwander, A. Meyer, and S. Chachakis, "Sprag overriding aircraft clutch," Tech. Rep. 105.7.11, Avco Lycoming Division Stratford CT, Stratford, CT, USA, 1972.

[2] J. Kish, "Helicopter freewheel unit design guide," Tech. Rep., United Technologies Corp. Stratford CT Sikorsky Aircraft Division, Stratford, CT, USA, 1977.

[3] C. Chassapis and G. Lowen, "High speed dynamics of a press feed mechanism, part i: theory, part ii: application and experiment," in Proceedings of ASME Mechanisms Conference, vol. 24, pp. 415-437, Orlando, FL, USA, 1990.

[4] T. Xu and G. Lowen, "A new damping model for nonlinear stiffness systems with variable preload displacements and constant amplitude decay ratios," Journal of Mechanical Design, vol. 116, no. 1, pp. 257-263, 1994. 
[5] T. Xu and G. Lowen, "A mathematical model of an overrunning sprag clutch," Mechanism and Machine Theory, vol. 29, no. 1, pp. 11-23, 1994.

[6] P. Vernay and G. Ferraris, "Comportement dynamique en torsion et en régime transitoire d'un démarreur de moteur d'avion," Mechanics \& Industrries, vol. 7, no. 2, pp. 147-153, 2006.

[7] P. Vernay, G. Ferraris, A. Delbez, and P. Ouplomb, “Transient behaviour of a sprag-type over-running clutch: an experimental study," Journal of Sound and Vibration, vol. 248, no. 3 , pp. 567-572, 2001.

[8] C. Huang, M. Liu, and Y. Zhao, "An analytical model of multiarc sprag clutch considering geometry and internal interaction during engagement," Shock and Vibration, vol. 2017, Article ID 2393578, 13 pages, 2017.

[9] Z.-h. Liu, H.-z. Yan, and Y.-m. Cao, "Design and analysis of logarithmic spiral type sprag one-way clutch," Journal of Central South University, vol. 22, no. 12, pp. 4597-4607, 2015.

[10] G. Lundberg, "Elastic contact between two semi-infinite bodies," Forschung auf den Gebiete des Ingenieurwesen, vol. 10, no. 5, pp. 201-211, 1939.

[11] P. Johns and R. Gohar, "Roller bearings under radial and eccentric loads," Tribology International, vol. 14, no. 3, pp. 131-136, 1981.

[12] H. Fujiwara and T. Kawase, "Logarithmic profile of rollers in roller bearing and optimization of the profile," Nippon Kikai Gakkai Ronbunshu C Hen (Transactions of the Japan Society of Mechanical Engineers Part C), vol. 72, no. 721, pp. 3022-3029, 2006.

[13] H. Fujiwara and K. Yamauchi, "Tolerance design of logarithmic roller profiles in cylindrical roller bearings," Journal of Advanced Mechanical Design, Systems, and Manufacturing, vol. 4, no. 4, pp. 728-738, 2010.

[14] S. Kamamoto, K. Fujimoto, and T. Yamamoto, "Research on crowning profile to obtain the maximum load carrying capacity for roller bearings," KOYO Engineering Journal, vol. 159, pp. 44-51, 2001.

[15] K. S. Kumar, R. Tiwari, and P. Prasad, "An optimum design of crowned cylindrical roller bearings using genetic algorithms," Journal of Mechanical Design, vol. 131, no. 5, article 051011, 2009.

[16] R. Teutsch and B. Sauer, "An alternative slicing technique to consider pressure concentrations in non-hertzian line contacts," Journal of Tribology, vol. 126, no. 3, pp. 436-442, 2004.

[17] D. Karnopp, "Computer simulation of stick-slip friction in mechanical dynamic systems," Journal of Dynamic Systems, measurement, and control, vol. 107, no. 1, pp. 100-103, 1985.

[18] R. Leine, D. Van Campen, A. De Kraker, and L. Van Den Steen, "Stick-slip vibrations induced by alternate friction models," Nonlinear Dynamics, vol. 16, no. 1, pp. 4154, 1998.

[19] K. Johnson and R. Cameron, "Fourth paper: shear behaviour of elastohydrodynamic oil films at high rolling contact pressures," Proceedings of the Institution of Mechanical Engineers, vol. 182, no. 1, pp. 307-330, 1967.

[20] T. Simpson, F. Mistree, J. Korte, and T. Mauery, "Comparison of response surface and kriging models for multidisciplinary design optimization," in Proceedings of 7th AIAA/USAF/ NASA/ISSMO Symposium on Multidisciplinary Analysis and Optimization, p. 4755, Long Beach, CA, USA, April 1998.

[21] N. Cressie, "The origins of kriging," Mathematical Geology, vol. 22, no. 3, pp. 239-252, 1990. 


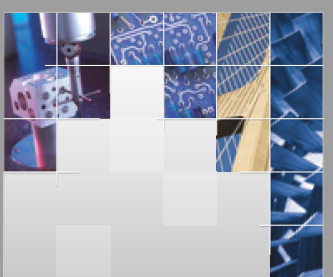

\section{Enfincering}
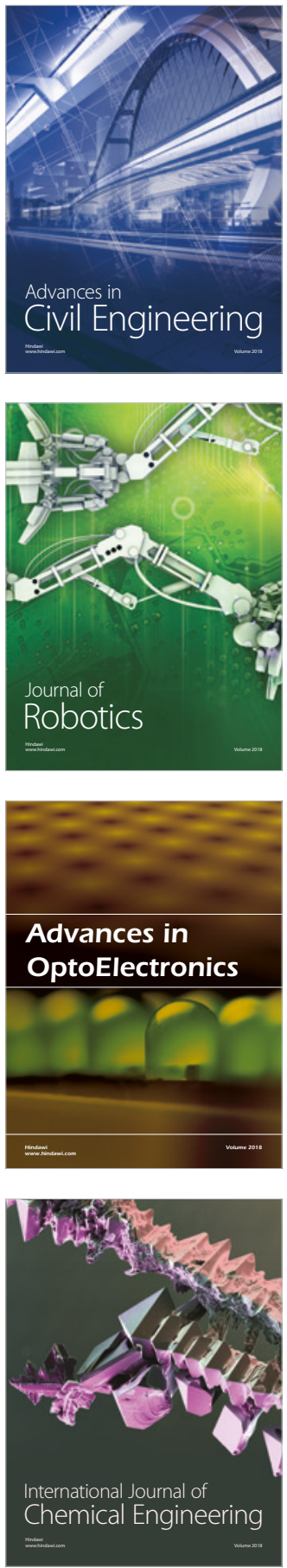

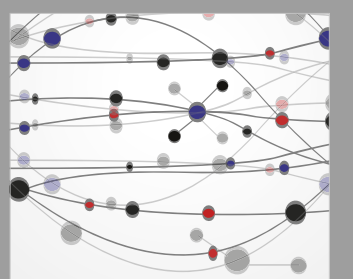

\section{Rotating \\ Machinery}

The Scientific World Journal

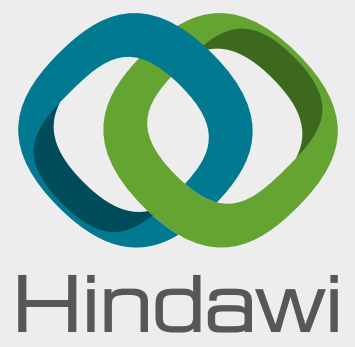

Submit your manuscripts at

www.hindawi.com
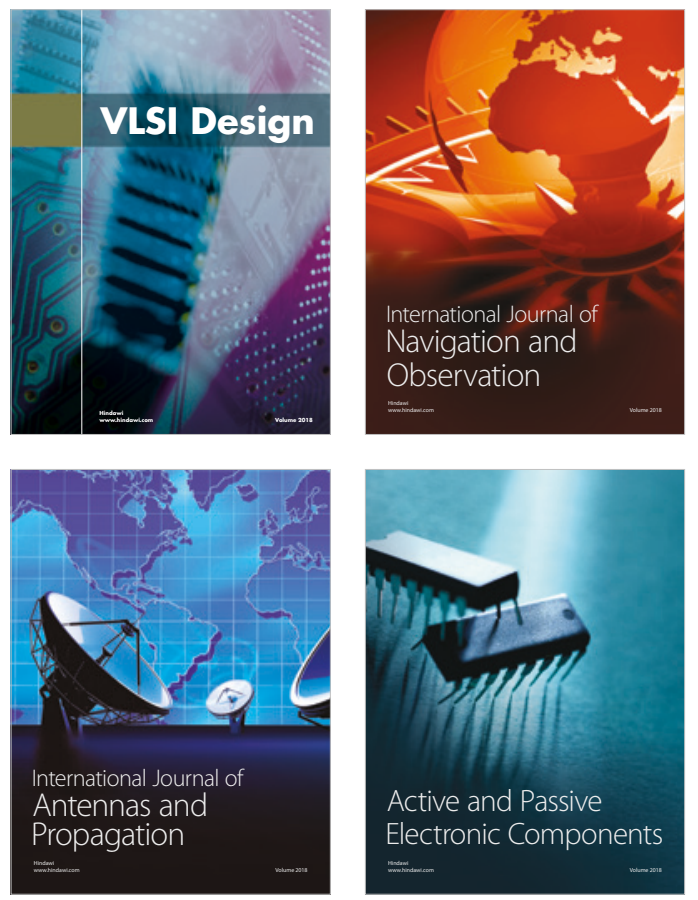
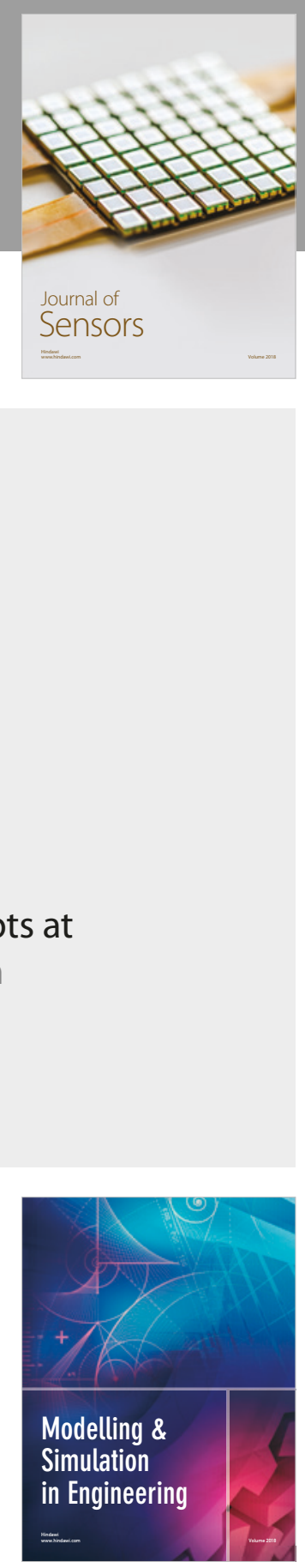

\section{Advances \\ Multimedia}
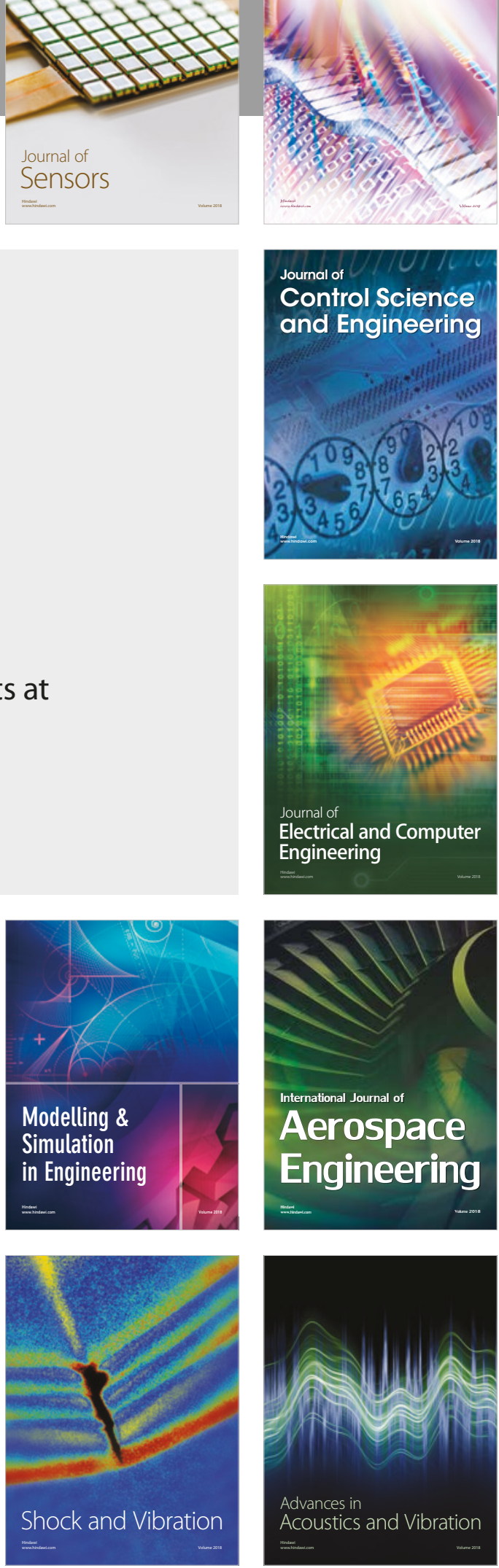